\title{
The Digital Economy: Approaches to the Definition and the Regional Dimension
}

\author{
Nataliya Puzina*, Irina Reutova, Nataliya Leshenko, Svetlana Khobotova, and Nataliya \\ Katunina
}

Dostoevsky Omsk State University, 644077 Omsk, Russia

\begin{abstract}
The article analyzes the practice of implementing measures for the development of the digital economy in the regions of the Russian Federation. The authors considered the question of the variety of definitions of the digital economy, and concluded that the world Bank provides the most appropriate definition of the "digital economy" within the framework of the topic under study. This allowed the regions of Russia to be singled out among the key participants of the digital economy. Based on the results of the study, the authors concluded that there is a high involvement of Russian regions in the processes of digital transformation of the economy. At the same time, there is a delay in legal regulation of the ongoing processes: the implementation of the Federal project "Digital region" in 2020 was suspended, but the regions continued to actively develop digital solutions and apply digital technologies to solve economic and social problems.
\end{abstract}

\section{Introduction}

Digitalization of national economies is the most important factor in the transformation of business and the public sector in modern conditions. According to 2020 Data, the EGovernment Development Index in Russia was 0.8244 , which corresponds to the 36th place out of 193 countries [1]. Countries are paying great attention to digitalization issues today. In 2018, a UN study of countries on the digitalization of the public sector of the economy was conducted, which emphasizes that digital transformation is necessary for the formation of a sustainable society [2]. Therefore, this issue is included in the UN agenda for sustainable development for the period up to 2030 [3]. A similar 2020 study found that many other countries and municipalities are implementing digital government strategies. Some of the new approaches that countries are taking in their quest for digital government transformation include introducing e-government as a platform, integrating online and offline multi-channel communications, flexibly developing digital services (supported by full government and society participation), integrating, expanding e-participation and partnerships, adopting data-centric approaches, strengthening digital capacity to deliver people-centred services, and innovating new technologies, such as artificial intelligence and blockchain, especially in the development of smart cities.

\footnotetext{
*Corresponding author: puzinanv@,omsu.ru
} 
The issue of digitalization of regions and cities is one of the most urgent for Russia. In this regard at the state level is developed by the Federal project "Digital region", whose main purpose is to rapidly introduce digital technology to the economy and social spheres of constituent entities of the Russian Federation for the economic growth, growth of welfare of the population. This interest and need for the development of the country's regions is observed not only at the level of the Federal government, but also on the part of organizations and society. In this regard, the purpose of this study is to assess the scale of implemented activities at the level of Russian regions in the context of the digital economy.

\section{Methods and Basic Definitions}

The methodological basis of this research is the theoretical positions of domestic and foreign researchers in the field of digital economy. To achieve this goal, we used content analysis, grouping, and comparison methods. The research uses materials from reports of the UN, higher school of Economics, and the results Of the program for the development of anti-crisis leaders and teams of the digital economy of CLICK, implemented within the framework of the Federal project "Personnel for the digital economy" of the national program "Digital economy of the Russian Federation".

In recent years, modern information sources have been actively using the terms "digital economy", "digitalization", "digital transformation" in the context of considering and applying information and communication technologies, artificial intelligence, in the current activities of corporations, regions, and the state. It can be noted that, while present in Russian practice, the concepts of "digital economy" and "digitalization" are not terminologically studied in the scientific literature. Some aspects of research in this area relate either to the use of digital technologies in relation to certain sectors of the economy, or to the description of digitalization tools.

We can also identify the following contradictions in the field under study:

- between theory and practice (the content of the concept of "digitalization" is not defined»);

- between the needs of economic entities in the use of digital technologies and the level of development of the industry;

- the practical application of the "digital economy" in Russia, according to the authors, is ahead of the development of theoretical and methodological developments in this area of research. There is a delay in the theoretical and methodological justification of the ongoing processes.

In this regard, there is a need to specify and clarify the main definitions in the digital economy, classification approaches, conceptual foundations of the digital economy, and develop methods for analyzing and evaluating the impact of digitalization on the performance of industries and corporations. In this paper, we will focus on the concept of "digital economy".

The term "digital economy" was first mentioned in the research of Western scientists Professor D. Tapscott [4], researcher R. Bukht and Professor R. Heeks [5]. However, their works do not reveal this concept, but rather describe its characteristics. In particular, D. Tapscott examines the evolution of economic models, the impact of digital technologies on business and management, and gives forecasts of future changes in the economy. In the works of R. Bukht and R. Heeks, the digital economy is considered at three levels: the digital sector, the digital economy itself, and the digitalized economy. The presented studies, as well as a number of others, focus on the components and attributes of the digital economy, the use of digital technologies, and state regulation of the digitalization of the economy. Digitalization is considered as "a process of socio-economic transformation 
initiated by the mass introduction and development of digital technologies, i.e. technologies for creating, processing, exchanging and transmitting information" [6].

The works of Russian authors are more often highly specialized, industry-specific, affecting the impact of digitalization on the development of a particular sector of the economy [7-10]. Often, Russian scientists do not distinguish between the digital economy and digitalization, between digitalization and digital transformation of the economy.the concepts are used as synonymous. Traditionally, the digital economy is considered through the creation, processing and use of a large array of information and knowledge presented in digital form [10].

The term "digital economy" is not disclosed in official documents. The national program "Digital economy of the Russian Federation" does not provide a definition, but contains a list of targets and indicators on the basis of which the digital economy is described as an economy aimed at:

- creating a stable and secure information and telecommunications infrastructure for high-speed transmission, processing and storage of large amounts of data, accessible to all organizations and households;

- use of mainly domestic software by state bodies, local self-government bodies and organizations [11].

We can agree with the point of view of $\mathrm{V}$. Tsirenshchikov, who questions the definition of "digital economy", and rather considers it as an incomplete transformation of all sectors of the economy during the process of digitization of information using computer technologies. At the same time, digitalization is a process of widespread introduction of information and communication technologies in the economy [6].

Taking into account the coverage of all spheres of the economy, we will use the world Bank's definition in this work:" the Digital economy is a new way of economy based on knowledge and digital technologies, within which new digital skills and opportunities are formed for society, business and the state " [12].

\section{Results}

In order to assess the scale of activities being implemented at the regional level in the context of the digital economy, it should be noted that a lot of work is being done in Russia on the practical implementation and development of digital services and technologies in public administration, including at the regional level. One of the directions of digitalization is the creation of control centers in Russian regions. A region management center (RMC) is a system for collecting, processing, and analyzing requests from residents of a given region. At the same time, information should be collected from various sources (websites, social networks, hotlines), where such requests are usually placed by residents. As of October 2020, 15 regions of the Russian Federation have completed the creation of RMC (Figure 1). 


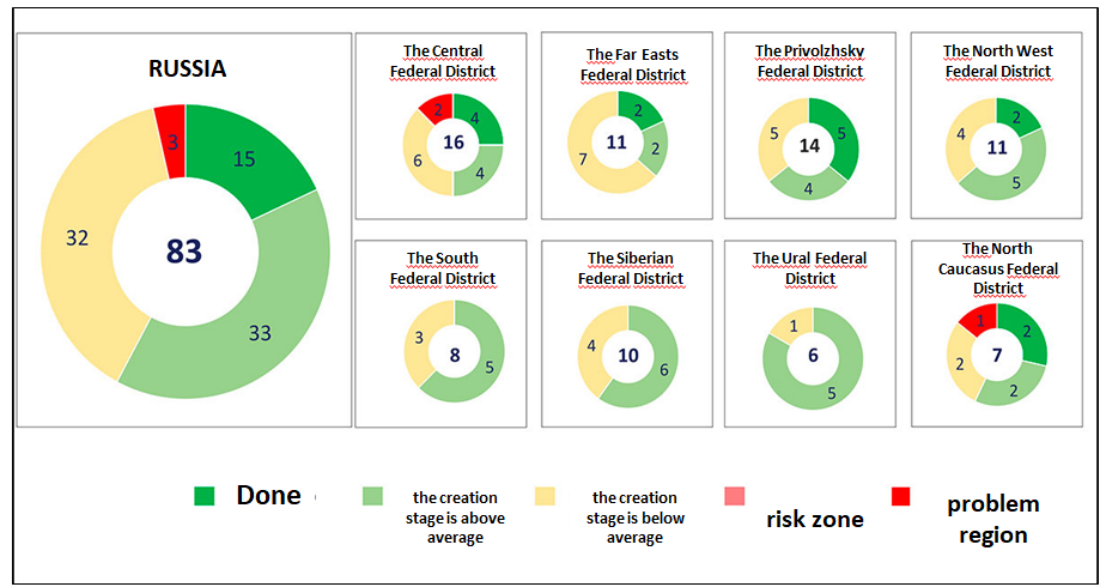

Fig. 1. Status of implementation of the sdgs according to the Federal districts, 27.10.2020 [13]

At the same time, the main directions of the Federal project "Digital region" are: housing and communal services, construction and energy, transport, social protection of the population, health care and education. These directions were fixed in the minutes of the meeting of the working group on the Federal project. Figure 2 shows the results of creating $\mathrm{RMC}$ in the context of the Russian Federation's constituent entities.

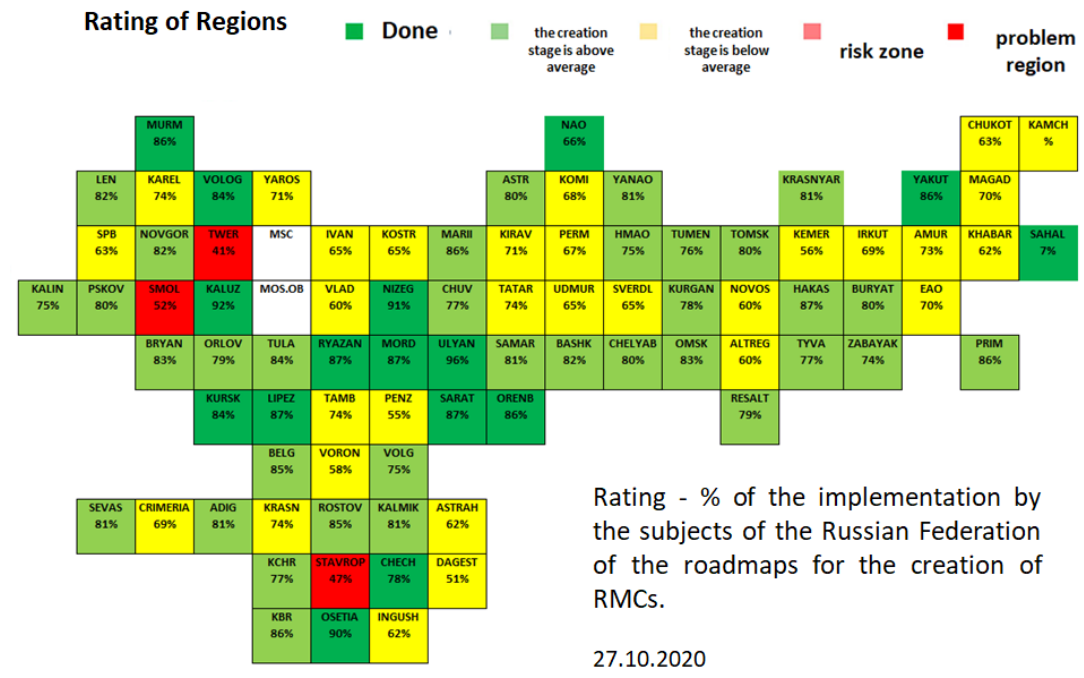

Fig. 2. Rating of regions for creating RMC [13]

By the end of 2020, all regions will complete work on creating sdgs. It is characteristic that back in April 2020, the block of measures for digitalization of regions was at the stage of study: 45 regions did not have a regional program for digitalization [14], while now several areas are actively developing.

The second area of digitalization at the regional level is the smart city project, which aims to increase the competitiveness of Russian cities. Within the framework of this project, the index of digitalization of urban economy "IQ of Russian cities"was developed. According to the results of 2018, the distribution of places for this indicator among cities with a population of one million is as follows: Moscow, Kazan, Saint Petersburg, Nizhny 
Novgorod, Ufa, Perm, Rostov-on-don, Novosibirsk, Samara, Omsk, Krasnoyarsk, Volgograd, Voronezh, Chelyabinsk, Yekaterinburg. The TOP-10 other major cities included: Khimki, Balashikha, Tyumen, Podolsk, Stavropol, Kaliningrad, Bryansk, Belgorod, Orenburg, Grozny [15]. Clearly, there is a correlation between the level of digitalization of the region and the level of digitalization of its individual cities, which act as a driver of digital development.

In a number of regions of Russia, the Digital twin project is being implemented, aimed at eliminating the shortcomings of the city's socio-economic development, for example, more effectively accounting for the city's resource flows, and assessing the impact of external factors. There are no unified data for regions in this area. At the same time, there are a number of successful examples of implementation: Moscow, St. Petersburg, Chelyabinsk and Leningrad regions, Volgograd and Tyumen regions.

In 2020, within the framework of the Federal project "Personnel for the digital economy" of the national program "Digital economy of the Russian Federation", a project was implemented to develop anti-crisis leaders and teams of the digital economy CLICK [16]. 651 teams from different regions of Russia took part in this project. The Rostov region and the Republic of Tatarstan represented the most participants among the regions. Developed and implemented projects of digital solutions are included in the list of cases of digital transformation. Figure 3 shows the estimated results of digital transformation.

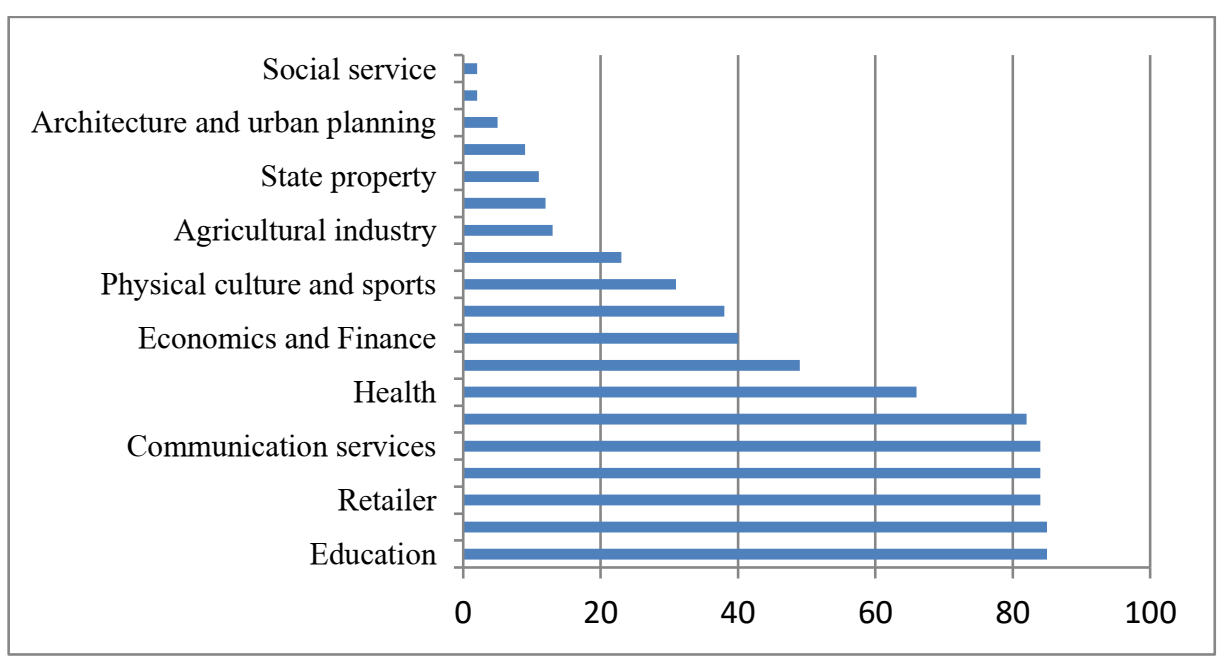

Fig. 3. Case studies of digital transformation, the number of covered regions of Russia

As can be seen from the figure, not only priority areas of digitalization of regions are being implemented. The transition to the digital economy covers many areas of the economy. At the Federal district level, the results of the analysis of digitalization examples are presented in Table 1. 
Table 1. The average number of cases of digitalization implemented in Federal districts

\begin{tabular}{|l|r|r|r|r|r|r|r|r|}
\hline $\begin{array}{l}\text { The average number of } \\
\text { cases of digitalization } \\
\text { according to the Federal } \\
\text { districts }\end{array}$ & $\begin{array}{c}\text { The } \\
\text { Central } \\
\text { Federal } \\
\text { District }\end{array}$ & $\begin{array}{c}\text { The } \\
\text { Fas } \\
\text { Feder } \\
\text { al } \\
\text { Distri } \\
\text { ct }\end{array}$ & $\begin{array}{c}\text { The } \\
\text { North } \\
\text { West } \\
\text { Feder } \\
\text { al } \\
\text { Distri } \\
\text { ct }\end{array}$ & $\begin{array}{c}\text { The } \\
\text { Privolzh } \\
\text { sky } \\
\text { Federal } \\
\text { District }\end{array}$ & $\begin{array}{c}\text { The } \\
\text { Siber } \\
\text { ian } \\
\text { Feder } \\
\text { al } \\
\text { Distri } \\
\text { ct }\end{array}$ & $\begin{array}{c}\text { The } \\
\text { South } \\
\text { Feder } \\
\text { al } \\
\text { Distri } \\
\text { ct }\end{array}$ & $\begin{array}{c}\text { The } \\
\text { Ural } \\
\text { Feder } \\
\text { al } \\
\text { istri } \\
\text { ct }\end{array}$ & $\begin{array}{c}\text { Crim } \\
\text { ea }\end{array}$ \\
\hline $\begin{array}{l}\text { Architecture and urban } \\
\text { planning }\end{array}$ & 2,0 & 0 & 1,5 & 0 & 1,0 & 0 & 2 & 0 \\
\hline State property & 1,3 & 0 & 1,3 & 1,0 & 1,0 & 0 & 1 & 0 \\
\hline $\begin{array}{l}\text { Government functions } \\
\text { and services }\end{array}$ & 1,4 & 1,0 & 1,0 & 1,8 & 1,7 & 1,0 & 1,2 & 2 \\
\hline Health & 2,9 & 4,3 & 3,4 & 2,8 & 2,4 & 2,0 & 2,2 & 0 \\
\hline Communication services & 1,0 & 1,0 & 1,0 & 1,0 & 1,0 & 1,0 & 1 & 1 \\
\hline $\begin{array}{l}\text { Culture, leisure and } \\
\text { tourism }\end{array}$ & 2,4 & 1,2 & 1,7 & 1,9 & 1,4 & 2,3 & 2,3 & 2 \\
\hline Education & 7,3 & 4,8 & 7,9 & 7,4 & 7,1 & 6,4 & 7,6 & 4 \\
\hline Public safety & 2,7 & 1,0 & 1,5 & 1,6 & 1,0 & 1,0 & 2 & 0 \\
\hline Society and media & 1,5 & 1,0 & 1,0 & 0 & 0 & 1,0 & 1 & 0 \\
\hline Industry & 3,8 & 2,9 & 4,2 & 4,3 & 2,8 & 2,6 & 5,2 & 1,5 \\
\hline Retailer & 4,8 & 4,0 & 4,5 & 4,9 & 4,5 & 4,4 & 4,4 & 4 \\
\hline Agricultural industry & 1,0 & 1,0 & 0 & 1,2 & 1,0 & 1,0 & 0 & 0 \\
\hline Social service & 0 & 0 & 0 & 1,0 & 0 & 0 & 1 & 0 \\
\hline Construction and housing & 3,6 & 3,1 & 2,5 & 3,7 & 2,9 & 2,7 & 3,8 & 1,5 \\
\hline Transport & 7,9 & 3,9 & 4,5 & 6,7 & 5,6 & 5,1 & 6,8 & 2 \\
\hline $\begin{array}{l}\text { Physical culture and } \\
\text { sports }\end{array}$ & 1,7 & 1,0 & 2,0 & 1,2 & 1,5 & 1,3 & 1 & 0 \\
\hline $\begin{array}{l}\text { Ecology and nature } \\
\text { management }\end{array}$ & 1,0 & 0 & 1,0 & 1,0 & 1,0 & 0 & 1 & 0 \\
\hline Economics and Finance & 1,8 & 1,7 & 1,6 & 1,6 & 1,8 & 1,7 & 1,6 & 1 \\
\hline $\begin{array}{l}\text { The amount covered by } \\
\text { the areas of digital } \\
\text { transformation }\end{array}$ & & & & & & & & \\
\hline & 14 & 16 & 16 & 17 & 14 & 17 & 9 \\
\hline
\end{tabular}

Today, among the available solutions to digitalization problems at the regional level, solutions in the fields of education and transport have been most developed. The least studied areas are social services, ecology, agriculture, architecture and urban planning.

\section{Conclusions}

The analysis of the development of digitalization processes at the level of Russian regions allows us to conclude that currently the task of inclusion in this process is set for all regions at the Federal government level. Some regions are actively developing platform solutions and services for the development of areas not specified in the Federal project "Digital region". As with the theoretical and methodological justification, there is a delay in the legal regulation of the ongoing processes: the implementation of the Federal project has been suspended, but the digitalization of the regions is proceeding rapidly.

\section{References}

1. E-government Survey 2020 (2020) https://publicadministration.un.org

2. Department of Economic and Social Affairs Public Institutions (2020). https://publicadministration.un.org/

3. The transformation of our world: an Agenda for sustainable development for the 
period till 2030 (2015), https://undocs.org/ru/A/RES/70/1

4. D. Tapscott, The Digital Economy: Promise and Peril in the Age of Networked Intelligence (1996)

5. R. Bukht, R. Heeks, International Organisations Research Journal, 29, 13 (2018)

6. V. S. Tsirenshchikov, Modern Europe, 88, 3 (2019)

7. E. S. Avdeeva, V. V. Erisco, Russia: tendencies and prospects of development, 7, 13 (2018)

8. L. P. Goncharenko, S. A. Sybain, Vestnik Universiteta, 7, 8 (2019)

9. E. B. Starodubtseva, O. M. Markova, Vestnik of Astrakhan State Technical University, 9, 2 (2018)

10. S. I. Chernykh, ETAP: Economic Theory, Analysis, and Practice, 14, 4 (2018)

11. Passport of the national project national program "Digital economy of the Russian Federation" (7, 2019) http://docs.cntd.ru/

12. What is the digital economy? Trends, competencies, and measurement, 89 (2019)

13. Results of the Russian President's order on the creation and operation of the regional management center (2020), https://d-russia.ru/

14. Current development projects in the field of digital economy in the regions of Russia (2019) https://ac.gov.ru/

15. IQ-cities index for 2018 (2018) https://minstroyrf.gov.ru/

16. Program for development of anti-crisis leaders and teams of the digital economy CLICK (2020), https://clickcdo.ru/ 